\title{
Rib Tubercle
}

National Cancer Institute

\section{Source}

National Cancer Institute. Rib Tubercle. NCI Thesaurus. Code C52729.

A bony prominence located at the junction of the neck and the body of a rib, which articulates with the transverse processes of the adjacent thoracic vertebrae, ribs eleven and twelve excepted. 